Max-Planck-Institut für demografische Forschung

Max Planck Institute for Demographic Research

Konrad-Zuse-Strasse 1 - D-18057 Rostock - GERMANY

Tel +49 (0) 3812081 - 0; Fax +49 (0) 3812081 - 202;

http://www.demogr.mpg.de

MPIDR WORKING PAPER WP 2012-028

NOVEMBER 2012

\title{
Regional Hot Spots of Exceptional Longevity in Germany
}

\author{
Rembrandt D. Scholz (scholz@demogr.mpg.de) \\ Sebastian Klüsener (kluesener@demogr.mpg.de)
}

This working paper has been approved for release by: Mikołaj Szołtysek (szoltysek@demogr.mpg.de), Deputy Head of the Laboratory of Historical Demography.

(C) Copyright is held by the authors.

Working papers of the Max Planck Institute for Demographic Research receive only limited review. Views or opinions expressed in working papers are attributable to the authors and do not necessarily reflect those of the Institute. 


\section{Regional Hot Spots of Exceptional Longevity in Germany}

Rembrandt D. Scholz and Sebastian Klüsener

Max Planck Institute for Demographic Research 


\begin{abstract}
In their contributions to the debate on exceptional longevity, several scholars have noted the existence of spatial hot spots, or areas with a high concentration of individuals who have survived to very high ages (e.g. Sardinia in Italy or Okinawa in Japan). However, most of these studies were based on a small number of cases. This study investigates the spatial pattern of exceptional longevity in Germany by place of birth and place of death. We used a large dataset of exceptional longevity that covered all recorded individuals who reached the age of 105 in Germany in the period 1991 to 2002 (N: 1,339). Our research results show that, even in Germany, with its troubled 20th-century past, most of the semi-supercentenarians reached the age of exceptional longevity in the same region in which they were born. The discovery of this highly localised pattern supports the view that an investigation of regional variation in exceptional longevity can produce meaningful results. In our analysis of spatial variation, we were able to detect hot spots of exceptional longevity in Berlin and in north-western Germany. These findings are remarkable, as life expectancy in Germany is currently characterised by a south-north gradient, with the areas of highest life expectancy at birth being located in the south. The observed pattern of exceptional longevity instead reflects the life expectancy at birth pattern in Germany in the early 20th century and to some degree also the current life expectancy at age 80 pattern. Our findings might be interpreted as support to the argument that early and late life conditions might play an important role in explaining spatial variation of exceptional longevity in Germany.
\end{abstract}




\section{Introduction}

In recent decades, the numbers of people who have reached the ages of 105 and above have increased dramatically. In their contributions to the debate on exceptional longevity, several scholars have noted the existence of spatial hot spots, or areas with a high concentration of individuals who have survived to very high ages. This includes, for example, men in Sardinia (Pes et al., 2011) and people living in Okinawa (Cockerham and Yamori, 2001, Willcox et al., 2008). The existence of such longevity islands has been linked to social conditions, such as variation in diets, as well as to genetic differences. However, the evidence cited in these studies is usually based on a small number of cases. Moreover, some scholars have pointed out that, for some of these supposed hot spots, the evidence might be an artefact attributable to not validating the data correctly (e.g. Poulain, 2011 on Okinawa). There are also principled arguments against such research, especially when contextual conditions are seen as important influencing factors, because researchers often do not have information on the migration histories of the observed individuals with exceptional longevity. Thus, they do not know in which different spatial contexts these individuals lived in different periods of their lives.

This paper uses a unique dataset of exceptional longevity, created as part of an age validation study of Germany, which covers all individuals who reached the age of 105 in Germany between 1991 and 2002. Our dataset contains information on 1,339 persons ${ }^{1}$. We address two main research questions. The first looks at what kind of pattern related to the distance between an individual's place of birth and the place of death ${ }^{2}$ can be observed. A very localised pattern would provide support for the application of spatial analysis techniques in investigating exceptional longevity, as it suggests that substantial portions of the population lived-at least in their final years-in the same geographic area as the one in which they were born. We are able to calculate the distance between place of birth and place of death at the municipality level. The second aim is to investigate to what extent we can detect a stable spatial pattern in the variation in reaching exceptional longevity in Germany. As we are dealing at the regional level with a small number of observations, we apply spatial Bayesian smoothing techniques

\footnotetext{
${ }^{1}$ This includes 961 persons born in present-day Germany and 378 individuals born outside of present-day Germany. For the second group, the complete validation procedure could not be carried out. See the data section for details.

${ }^{2}$ The place of birth refers to the place of residence of the mother at the time the child was born, while the place of death refers to the place of residence of the individual at the time of death. For those semi-supercentenarians who were still alive in 2002, we use the place of residence at that time.
} 
(Marshall, 1991). We are able to calculate the rates of exceptional longevity, both by place of death as well as by place of birth, which allows us to compare the resulting spatial pattern for consistency. We further investigate the consistency of our findings by repeating the analysis while varying both the definitions of exceptional longevity, as well as the definitions of the base population. We also consider different levels of spatial aggregation to investigate to what extent our findings are geographic-scale dependent.

Our study uses one of the biggest datasets worldwide covering validated semisupercentenarians, for whom information on place of birth and place of death are available. To our knowledge, it is also one of the first studies that looks at the distances between the place of birth and the place of death of individuals with exceptional longevity at the municipality level. Another innovative element of this study is that it links data with historical GIS files, which allow us to relate events of exceptional longevity by place of birth with the number of births in a region at the time when the semi-supercentenarians were born, while controlling for changes in the regional administrative boundaries within Germany.

\section{Research on Exceptional Longevity}

Exceptional human longevity has long been of interest to the general public, as well as to scientists. An early work using validated individual-level data on exceptional longevity in Germany was carried out by Geissler (1884). He looked at the socio-economic status of individuals with exceptional longevity in Saxony. After validating cases of exceptional longevity in the census of 1880, he determined that, at that time, no individual older than 99 years of age was living in Saxony-which was, in the late $19^{\text {th }}$ century, one of the most developed regions in Europe. His definition of exceptional longevity was from today's point of view very low, as it included all people aged 80 and above.

Existing research results on the longevity revolution suggest that contextual conditions are very important for our understanding of the improvements in life expectancy in recent decades and centuries. While the life expectancies of European populations in the $18^{\text {th }}$ century differed very little from those of hunter-gatherer populations, longevity has changed radically since then (Burger et al., 2012). The context-related explanations for exceptional longevity include geographical differences in diet (Willcox et al., 2006), as well as differences in occupational activities (Pes et al., 2011). In addition, there is also evidence that early life contextual conditions have an impact on chances to reach exceptional longevity. For Germany it has 
been shown by Scholz et al. (2005) that children born in winter have a higher likelihood to reach exceptional longevity. This research used the same dataset that we are using, which covers cohorts born in the late $19^{\text {th }}$ century.

However, although changes in contextual conditions are likely to explain most of the changes in average life expectancy, it cannot be ruled out that genetic variation plays a role in exceptional longevity. It is important to note that reaching exceptional longevity is, by definition, a highly selective event ${ }^{3}$. In order to reach such an age, a person might need to have a specific level of genetic robustness that is not shared by the majority of the population (see, e.g., Hjelmborg et al. 2006; Sebastiani et al., 2012).

In this research project, we are not able to examine these issues in detail, as our dataset of individuals with exceptional longevity does not contain information on genetic or socioeconomic characteristics. However, we can compare spatial variation in exceptional longevity with historic and present spatial patterns in aggregate demographic characteristics, such as life expectancy or weight/length at birth. This will allow us to shed some light on general aspects of spatial variation in exceptional longevity.

\section{Data}

For our research project, we used a dataset of persons who reached ages of 105 and above in the period 1989-2002 while living in Germany (Maier and Scholz, 2003 and 2004; Scholz and Maier, 2005). The dataset was created as part of the International Database on Longevity (IDL) (Maier and Scholz, 2010; Doblhammer et al., 2005). This was done in a three-stage process. In a first step, the Office of the President of the Federal Republic of Germany (Bundespräsidialamt) provided a list of all individuals aged 105 and above who received a congratulatory letter on the occasion of their birthday from the Federal President in the period from 1989 to $2002(\mathrm{~N}=1,487)^{4}$. Second, the local Residence Registry Office (Meldebehörde) was asked for the vital status of the person and the person's place of birth. Third, the Office of Vital Records (Standesamt) at the person's place of birth was asked to confirm the date and

\footnotetext{
${ }^{3}$ The definition of which ages represent exceptional longevity can vary over time.

${ }^{4}$ This list is based on information provided by the local Residence Registry Offices, who report inhabitants who reach, or who are about to reach, the age of 105 to the Office of the German President.
} 
place of birth ${ }^{5}$. An individual was considered age-validated if the Residence Registry Office provided a late-life document showing that the person had reached age 105, and the Office of Vital Records provided an early-life document that confirmed the person's place and date of birth. The completeness of the database was checked by comparing the information in the database to the death counts in the German data of the Human Mortality Database (HMD). The comparison showed that the database of individuals aged 105+ covered over $90 \%$ of all HMD death counts in this age group in Germany in the observation period (Scholz and Maier, 2005).

After finishing the age validation process, the whole dataset of German semisupercentenarians was anonymised in order to comply with German data protection regulations. Different anonymised datasets were produced for the analyses and validation procedures. One of these datasets is the anonymous data file used for this study, which provides information on place of birth and place of death at the municipality level (Scholz, 2003). For our analysis, we excluded all persons in the dataset who died before 31 December 1990. This was necessary because, until the reunification of Germany, only citizens living in West Germany were included in the dataset, which would create a bias in the analysis of spatial patterns. This left us with 1,339 persons aged 105 or above who lived during the period of observation in Germany. There are clear differences by sex, as 1,184 of the individuals are female (88.4\%). Of the 1,339 persons, 961 were born within the borders of present-day Germany (71.6\%), while another 276 were born in territories that were part of the German Empire at the time of birth (20.6\%). Less than 8\% (102) were born outside of the German Empire, most of them in Eastern Europe. The latter two groups have to be treated with caution, as their dates of birth have not been validated by contacting the Office of Vital Records at the place of birth. They are excluded from our analyses of exceptional longevity by place of birth, but are considered in the analyses by place of death ${ }^{6}$.

Unfortunately, the nature of our dataset implies that we did not have information on individuals who were born in Germany and who reached the age of 105 abroad. However, we benefited from the fact that levels of outmigration from Germany have been low over the last 100 years. The last major wave of outmigration in the $19^{\text {th }}$ century ended in the 1880 s, around the

\footnotetext{
${ }^{5}$ This third step was only carried out for those individuals who were born in places located within the borders of present-day Germany.

${ }^{6}$ We included them in the analysis by place of death because we were not able to distinguish war refugees from former German territories and naturalised foreigners from the population at risk.
} 
time when the oldest semi-supercentenarians in our dataset were born (German Empire Statistical Office). Outmigration would be of concern for our analysis if it were concentrated in certain regions of Germany.

Information on the location of the place of birth and place of death was derived at the municipality level from the VG 250 GIS-file of the Federal Agency of Cartography and Geodesy (BKG, 2007), which displays administrative boundaries at a scale of 1:250,000. For the municipalities of birth which were later dissolved or incorporated in other municipalities, we took the code of the municipality to which the area of the municipality of birth belongs today. From the GIS file, we derived for each municipality the north and east value of the areal centroid $^{7}$. In addition, we used shapefiles of the MPIDR Population History GIS Collection, which were developed in part based on the VG 2500 (scale 1:2,500,000; BKG, 2009). From this collection we made use of district-level maps of 2000 and 2004 and a district-level map of the German Empire for the year 1894 (see Klüsener et al., 2012, for details).

In order to analyse spatial variation in exceptional longevity, we had to define a population at risk. When looking at the place of death, we did not consider it adequate to use the total population in an area as the population at risk, as this would have created biases dependent on whether a region had experienced substantial immigration or outmigration in recent decades. Bavaria, for example, has registered substantial immigration since the 1960s, but because most of these migrants were of working age, immigration affected the total population number, but the elderly population who could potentially reach the age of 105 in our period of observation were affected to only a small extent. We therefore decided to use only age groups of the elderly to define the population at risk, as they are less affected by selective migration processes. In attempting to do this, we were faced with the limitation that official statistical publications do not provide detailed information on the elderly population by age group. All individuals aged 75 and above are placed in a single category. We therefore had to use an alternative source to derive more detailed information. We decided to generate this data from the German pension insurance system dataset (FDZ RV, 2008), which contains information on all individuals who have ever made contributions to the German pension fund, or who have gained rights to pension payments for other reasons (e.g. widows or mothers for the

\footnotetext{
${ }^{7}$ These are just approximations of the place of birth and the place of residence at age 105+/death, as we lack exact information. This might create small biases in our analysis of distances. This bias might also vary spatially, as the average area of municipalities differs between the federal states of Germany (Laux, 2001).
} 
births of children). This dataset covers approximately 95\% of the total population living in Germany. From these data we derived for the year $2005^{8}$ regional population data by the following age groups: 75-84, 85-94 and 95+. We compared aggregates of these data at the district level with official statistics for the population aged $75+$ for the year 2005, with the correlation coefficient being 0.99 . This gave us confidence that the German pension fund data are suitable for defining populations at risk. We generated the age group information for the total population, as well as for the male and female populations.

For our analyses based on place of birth, we used district-level data on the average number of births in the period 1894-1896 (German Empire Statistical Office, 1901). These three years were chosen for two reasons: one was data availability, and the other was that these birth years were highly represented in our dataset. Approximately $30 \%$ of our individuals were born in these three years, and another 20\% were born in the years 1893 and 1897. This suggests that the birth years 1894-1896 are a good representation of the population at risk for the analysis by place of birth. Information on the spatial variation in birth weight and birth length, which is used as a crude indicator to explore whether genetic factors might play a role in shaping the spatial variation in exceptional longevity, was generated from German Birth Register Data (FDZ, 2012).

\section{Methods}

Our analysis is divided into two parts: the first part is an investigation of the distances between place of birth and place of death, while the second part is an investigation of the spatial variation in exceptional longevity by both place of birth and place of death. The distance calculation between a person's place of birth and place of death is based on great circle distances $^{9}$. From this data we derived density curves and descriptive statistics.

In the second part of our analysis, we studied spatial pattern of exceptional longevity by both place of birth and place of death. We aggregated the individual data at the regional level,

\footnotetext{
${ }^{8}$ This would have been even more precise if we had generated the information on the population at risk retrospectively for the time when the individuals with exceptional longevity were in these age groups. However, data availability constraints did not allow us to do so.

${ }^{9}$ Great circle distance is the shortest distance between two points on the surface of a sphere (in our case, the Earth). For additional details, see Banerjee (2005).
} 
partly in order to comply with German data protection regulations ${ }^{10}$. In our analysis, we used different definitions of the event of interest, as well as of the population at risk, in order to test to what degree the emerging spatial patterns of exceptional longevity were stable across different definitions. This included looking at exceptional longevity by sex (total, male, female) or using different age categories as population at risk $(75+, 85+, 95+)$. We also replicated our analyses at different geographic scales, as the choice of the geographic scale can have substantial implications for outcomes and interpretations. This issue is commonly referred to as the modifiable areal unit problem (Openshaw 1983). We based our analysis on the following administrative divisions: German federal states $(\mathrm{N}=16)$, Regierungsbezirke $(\mathrm{N}=40)$ and regional planning regions $(\mathrm{N}=97) .{ }^{11}$ However, at all three levels we encountered the problem that some metropolitan areas constitute their own regions (Berlin, Hamburg), while others are incorporated into bigger regions. We therefore decided for all three divisions to also carve out the other two big cities in Germany with more than one million inhabitants: Munich in southern Germany and Cologne in western Germany.

In comparing the events of exceptional longevity by place of birth with the number of births that occurred at the time the semi-supercentenarians were born, we were faced with the challenge that Germany has undergone substantial reforms of administrative boundaries at all of the levels considered. In order to get an estimate of the number of births that occurred within the regions currently existing, we used an areal interpolation procedure based on areal weighting, ${ }^{12}$ which was suggested by Goodchild and Lam (1980).

\footnotetext{
${ }^{10}$ German Data Protection regulations require that in order to calculate regional rates based on individual-level information, one needs to have in each region at least three individuals.

${ }^{11}$ We use the administrative division as of 31 December 2002.

12 The areal interpolation method is based on the assumption that births by place of residence are distributed homogenously across space within the source regions, for which we have data. This is a strong assumption, as it is unlikely that the population is homogenously distributed across space, nor can we expect the occurrence of birth events to be constant across each source region. However, the potential error emerging from the estimation is largely dependent both on the geographic detail of the source regions, as well as on the geographic detail of the target regions, for which the estimations are produced. The higher the geographic detail of the source regions in comparison to the target regions, the smaller is the potential error emerging from the estimation procedure. As we had very detailed source data at the level of 947 districts for the births that occurred 1894-1896, while the number of our target regions varied between 18 (16 federal states and two cities) and 99 (97 regional planning regions and two cities), we decided not to use more complex estimation methods, such as, for example, the EM algorithm (see Gregory 2002). In order to derive the estimates, we applied a spatial intersection, in which we
} 
In mapping the spatial pattern of exceptional longevity, we were faced with the problem that we were dealing with a rare event, which implies that our analysis might be distorted by random noise. We therefore used the Local Empirical Bayes Smoother (Marshall, 1991; Bailey and Gatrell, 1995), which allowed us to derive a more stable pattern by adjusting the raw rates in each region based on Bayesian principles using information from neighbouring regions. The Local Empirical Bayes Smoother is related to the Global Empirical Bayes Smoother. In the latter prior mean and variance are assumed to be constant across a sample. In the Local Empirical Bayes Smoother, the prior is derived for each region i from a subsample, which only includes regions $j$ in the neighbourhood of each region $i$ (for neighbourhood definitions, see below). This is based on the assumption that nearby regions $\mathrm{j}$ are, in terms of structures and processes, more similar to a region i than more distant regions. To this is also referred to as the First Law of Geography (Tobler, 1970).

We illustrate our Bayesian smoothing technique with a simple example. Imagine a country with 10 regions and a total population at risk of reaching exceptional longevity of 10,000 individuals (in average 1,000 per region). In our example, one sub-region i has just a population at risk of 100 persons and recorded two persons reaching exceptional longevity. As the population at risk and the number of events are very small, it is likely that this outcome is highly influenced by randomness. Now imagine, this region i has just one neighbouring region $\mathrm{j}$, which has a population at risk of 1,000 individuals and recorded 40 events of exceptional longevity. Based on Bayesian principles this information is much more reliable as it is based on a higher number of individuals at risk. This information from neighbouring region $\mathrm{j}$ is taken into account in the smoothing of the rate of region $i$, following the assumption based on the First Law of Geography that nearby regions are more similar in the processes influencing exceptional longevity compared to more distant regions. In our example, the algorithm would determine the number of events recorded in region i to be with two out of 100 rather small in comparison to 40 out of 1,000 in region $\mathrm{j}$ and would adopt the rate of region $\mathrm{i}$ in the direction of the rate of region $\mathrm{j}$, taken the population at risk in the two regions into account as a measure for the reliability of the information.

The prior mean for the raw rate at region $\mathrm{i}$ is derived by:

intersected a GIS polygon file with border and area information on the source regions with the file of the target regions (Goodchild and Lam 1980). We thereby obtained a GIS dataset with the smallest common polygons (also called zones of intersections), which enabled us to reconstruct the values for the target regions. 


$$
\hat{\mu}_{i}=\frac{\sum_{i \in J_{i}} O_{i}}{\sum_{i \in J_{i}} P_{i}^{\prime}}
$$

where $\mathrm{J}_{\mathrm{i}}$ represents a set of neighbours $\mathrm{j}$ to a region $\mathrm{i}$, including $\mathrm{i}$ itself, based on a chosen neighbourhood definition (Anselin et al., 2006). O denotes the observed events and $\mathrm{P}$ the population at risk. The local estimator for the prior of the variance is derived as follows:

$$
\hat{\sigma}^{2}{ }_{i}=\frac{\left\lfloor\sum_{i \in J_{i}} P_{i}\left(\hat{\pi}_{i}-\hat{\mu}_{i}\right)^{2}\right\rfloor}{\sum_{i \in J_{i}} P_{i}}-\frac{\hat{\mu}_{i}}{\bar{P}_{i}{ }^{\prime}}
$$

where $\hat{\pi}_{i}$ denotes the estimated rate for region i and $\bar{P}_{i}$ 'is the local average population at risk, which is derived as follows:

$$
\bar{P}_{i}^{\prime}=\frac{\sum_{i \in J_{i}} P_{i}}{N}
$$

For the definition of the neighbourhood, different strategies are feasible. One approach is to define it based on contiguity, defining all regions that border each other in at least one common point as neighbours (also referred to as the first-order queen's definition). Other strategies are based on k-nearest neighbours or distances between centroids of regions. In our analysis, we replicated the analysis using different neighbourhood definitions as another consistency check.

We should note that, because our dataset contains metropolitan areas that are defined as regions, using the Local Empirical Bayes Smoother could be problematic. While for most regions it can be assumed that neighbouring regions have many similarities in terms of socioeconomic and ecological conditions, this might not be the case for metropolitan areas and the surrounding regions. This implies that we should interpret the resulting pattern of smoothed rates around metropolitan areas such as Berlin or Hamburg with special care.

\section{Results}

We will first look at the results of our analysis of the distance between place of birth and place of death. Interestingly, for most of the individuals in our dataset, the analysis shows a highly localised pattern. Of the 961 persons who were born within the present-day borders of Germany and who had reached the age of 105 while living in Germany, 301 were, at the age 
of 105+, still/again living in their place of birth (approximately 31\%). The median distance between place of birth and place of death was $25 \mathrm{~km}$ (see upper graph in Fig. 1). The pattern for individuals born in western Germany, where the median distance was just around $15 \mathrm{~km}$, was even more localised. For those born in eastern Germany, on the other hand, the median distance was, at $104.6 \mathrm{~km}$, much higher, which probably reflects in part the impact of the division of Germany on the east-west migration pattern (see middle graph in Fig. 1).

[Figure 1 about here]

However, as big cities in particular are likely to attract people from more distant locations, there might be a substantial degree of variation within Germany. We therefore did another analysis in which we identified all of the individuals who were living in one of the four biggest cities of Germany (Berlin, Hamburg, Cologne, Munich) at the time of death (see lower graph in Fig. 1). The pattern was indeed less localised for those individuals than for semisupercentenarians living elsewhere in Germany. However, this was only true for distances of between zero and $50 \mathrm{~km}$, as many semi-supercentenarians living in the four biggest cities were not born in the city itself, but in its immediate surroundings. If we look at the median distance between place of birth and place of death, we can see that it was, at around $31 \mathrm{~km}$, also quite low for this group ${ }^{13}$.

Overall, our results suggest that, even in Germany, with its troubled $20^{\text {th }}$-century past, the distance between place of birth and place of death was very small for most of the individuals observed in the dataset. This was the case even if they lived in big metropolitan areas, which had substantial rates of immigration over the past 100 years. Our finding that the distances between place of birth and place of death were highly localised for a large number of individuals in the dataset lends support to the argument that an analysis of spatial patterns of exceptional longevity would produce meaningful outcomes. But beyond this, it also raises the question whether this result could be expected or whether it is a rather unusual finding, which might potentially stem from differential mortality between stayers and movers at high age.

Theoretically, one might argue that individuals of high age who still reside in their birth region might have competitive advantages compared to persons of the same age who life outside their birth region. The former group might have better access to social capital in the form

\footnotetext{
${ }^{13}$ We also looked at differences by sex, but because we did not find substantial differences, we do not present the results here.
} 
of a higher number of nearby living family members able to assist the person in daily activities, long-standing friendships with people living in the same place, or better contacts in the neighbourhood. An alternative explanation might be that the observed pattern of small distances between place of birth and place of death simply represents the net lifetime migration pattern typically for this cohort of Germans. It is not so easy to derive an answer for this question, as with increasing age persons are likely to become frailer. This elevates the risk that they leave their old place of residence to move to their children or in a retirement home, which might be situated in another locality. Therefore, an ideal research design would require longitudinal information on the observed persons at least from age 90 on with regularly updated information on their health status and migration histories. We do not have such longitudinal information available. Unfortunately, there is also no recent German census data available, which would allow us to derive information on lifetime migration for age groups below 105 or for our observed cohorts at an earlier point in time.

But we are at least to some degree able to answer the question by analysing individual-level data from the Swiss censuses of 1970, 1980, 1990 and 2000, which contain information on lifetime net migration. These are available as 5\%-sample IPUMS-files (Minnesota Data Center, 2011). Switzerland and Germany are neighbouring countries, which share cultural links as two third of the Swiss population speak German as mother tongue. Thus, we believe that the two countries might also share similarities in lifetime net migration patterns. The Swiss dataset does not allow us to calculate distances between place of birth and place of death, but contains information whether a person still lives in the municipality in which the birth was registered. In addition we have information on the age of a person. However, a limitation is that the sample has been top-coded at the age of 95+ years, so that we cannot look at the highest ages separately. As we have data of four cross-sections spanning a period of 30 years we can analyse it both from an age as well as a cohort perspective.

In 1970, around 30\% of the Swiss population in the age categories above 90 was still living in their place of birth, while in the later censuses the level was a little bit lower (20-30\%). This corresponds to our finding that around $31 \%$ of our semi-supercentenarians lived/died at age 105+ in their place of birth. This might be interpreted as support for the argument that the pattern we detected is typical for the birth cohorts under observation. Also the cohort perspective does not provide evidence for the argument that people reaching high ages in their place of birth have a longevity advantage over persons that live outside of their birth municipality. For the Swiss cohorts born between 1885 and 1897 that approximately correspond to the co- 
horts covered by our semi-supercentenarian dataset, we have data on lifetime migration in 1970 and 1980 available. The youngest birth years are also represented in the 1990 data. In 1970, these cohorts were 73 to 85 years old, in 1980 83-95, in 1990 93-95. But none of these 13 birth cohorts experienced between the censuses an increase in the share of persons residing in their place of birth, which could be interpreted as hinting in the direction that this group has a longevity advantage. Overall, the analysis of the Swiss data suggests that our lifetime migration pattern derived for the German semi-supercentenarians is not unusual for these birth cohorts in a central European context. It also provides no indication for mortality differentials between stayers and movers at high ages. However, in order to answer the latter question in a conclusive manner, a longitudinal research design would be required. Another limitation of the Swiss data is that the age categories above 95 are top-coded, as the mortality differentials might only emerge at ages above 100 or 105, when most of the surviving persons are dependent on assistance in daily activities.

We will now turn to the second part of our investigation, which looked at spatial variation in exceptional longevity across Germany. In this section, we will only present the results at the Regierungsbezirk level, while omitting the results from the other two geographic scales at which we replicated the analysis (German states, regional planning regions). This is because the resulting spatial pattern turned out to be quite similar for all three of the geographical scales. Therefore, we decided to focus on the results at the Regierungsbezirk level, as doing so provides a good balance between the number of events of exceptional longevity within a region and the need for a certain level of regional detail.

In Fig. 2 we present the spatial pattern of exceptional longevity at the Regierungsbezirk level, with the left map showing the spatial pattern by place of birth, and the right map displaying the pattern by place of death. For the latter we used the population $95+$ as a base population ${ }^{14}$. Overall, the patterns of the two maps do not differ substantially. This was expected given the results of the first part of the analysis, which showed that most of the individuals with exceptional longevity died in the region in which they were born. The results do not differ substantially if we repeat the analysis for different populations at risk (e.g. people aged 85+ or women only).

\footnotetext{
${ }^{14}$ Please note that the rates displayed on the maps cannot be interpreted as survival rates, as, for example, the number of years in which the semi-supercentenarians were born is bigger than the number of birth years from which we derived the number of births.
} 
[Figure 2 about here]

In both maps, Berlin stands out as a local hot spot of exceptional longevity. It is the only area in eastern Germany with high rates of exceptional longevity. However, our data do not allow us to differentiate the data by West and East Berlin. This is unfortunate, as we would expect to find a particular concentration of semi-supercentenarians in the western part of the city, which belonged to West Germany during 1945-1990. As a result, the population of this part of the city benefited from innovations such as the cardiovascular revolution (Meslé and Vallin, 2002) decades earlier than the population in East Berlin. However, as the former capital of East Germany, East Berlin was also privileged in terms of access to medical services relative to other parts of the German Democratic Republic. Therefore, it might at least be a relative hot spot compared to the other eastern German regions.

Hamburg also displays high rates of exceptional longevity, though it forms part of a larger cluster in north-western Germany that also covers Schleswig-Holstein, Bremen and parts of Lower Saxony and Westphalia (Fig. 2). The cities of Cologne and Munich, on the other hand, cannot be characterised as hot spots of exceptional longevity in a German-wide comparison, although Munich seems to be a local hot spot relative to its surrounding areas.

The spatial pattern of exceptional longevity is somewhat surprising, as Germany is currently characterised by a south-north gradient in life expectancy at birth, with the areas of highest life expectancy being predominantly located in the south (see Fig. 3, bottom). The observed pattern of exceptional longevity instead reflects spatial variation in life expectancy at birth that prevailed in Germany in the early $20^{\text {th }}$ century, when the regions of northern Germany reported the highest levels (see Fig. 3, top). However, the current spatial pattern of variation in life expectancy might vary dependent on which age is considered. It might look very different for life expectancy at age 60 and age 80, as e.g. access to emergency care and quality of elderly care might vary across regions. Therefore, we also contrasted our findings to life expectancy data at ages 60 and 80 (SB, 2012 and own calculations ${ }^{15}$ ). This data we were only able to obtain at the level of the federal states from the 1970s on. Variation and trends in life expectancy at age 60 data show no strong divergence from the life expectancy at birth data. One important point, however is that the north German states of Schleswig-Holstein, Hamburg and Bremen managed to report life expectancies at birth and age 60 above the German average up until the 1990s, which might partly explain why they constitute hot spots of excep-

\footnotetext{
${ }^{15}$ Based on data provided by the state statistical offices.
} 
tional longevity for the period of our study (1991-2002). Berlin, on the other hand, neither reported above average life expectancies at birth nor at age 60 throughout the last 40 years. But the picture looks different for life expectancy at age 80, where Berlin consistently reports levels above the German average for the period for which we have data for all German states available (2002-2010). In 2002/2004, only three of the 16 German states had higher values than Berlin. These were the other two German city states Hamburg and Bremen as well as Baden-Württemberg in the Southwest.

One reason why Berlin and the other two city states perform so well at higher ages might be better access to improvements in health care e.g. in the area of emergency care and medical technologies. We already mentioned that East Berlin was privileged as capital of the German Democratic Republic when it came to health care investments. But also West Berlin was to some degree privileged in the Cold War period, as it served as a show window to Communist Europe. Evidence that bigger cities had better access to new medical technology is e.g. presented by Kirchberger (1994, p. 187). Another explanation for the high concentration of semisupercentenarians in Berlin might also be related to the unique history of the town in the $20^{\text {th }}$ century. Most big cities in Germany experienced substantial suburbanisation processes in the 1950s and 1960s, in which parts of the socio-economically advantaged population moved to places outside the city (e.g. Lake Starnberg region South of Munich or Hunsrück region North of Frankfurt). In West Berlin these suburbanisation processes could only start after 1990, which might also have contributed to the high concentration of semi-supercentenarians in the city itself.

[Figure 3 about here]

However, next to contextual conditions in early and late life, also alternative explanations cannot be ruled out, especially for the hot spot of exceptional longevity in north-western Germany. Another aspect in which north-western Germany stands out from the rest of Germany is in the variation of the mean weight and length at birth. Unfortunately, we have regional information on these indicators for the last 20 years only. However, over this time period, the spatial variation of these indicators remained rather stable. Therefore, we assume that these differences might already have existed in the $19^{\text {th }}$ century. Fig. 4 shows the spatial variation in average birth weight and length in Germany in 2009. The pattern suggests that the highest birth weights and birth length can be observed in north-western Germany. Birth weight and length are again influenced by many indicators, which can be related to socioeconomic (Koupilová, 1998; Koupilová, 2000) or genetic characteristics (Clausson et al., 
2005). But if this gap had already existed in the late $19^{\text {th }}$ century, children born in northwestern Germany might have been more robust than children born in other parts of the country. This may also be one explanation for why life expectancy was higher in north-western Germany at that time (see Fig. 3). However, further research is needed to look into this alternative explanation.

[Figure 4 about here]

\section{Conclusion and Outlook}

Overall, our findings show that, even in Germany, with its troubled $20^{\text {th }}$ century past, the distance between place of birth and place of death is very small for most of the semisupercentenarians observed in the dataset. This lends support to the argument that an analysis of spatial patterns of exceptional longevity can provide meaningful results, even if we only know the place of birth and place of death of a person. Our analysis of the spatial variation in exceptional longevity resulted in a clear spatial pattern. Consistency checks, in which we varied definitions of the event of exceptional longevity and the population at risk, did not alter our outcomes substantially. Hot spots of exceptional longevity could be identified in Berlin and north-western Germany, which is remarkable because the areas with the highest life expectancy at birth are currently located in southern Germany. The pattern resembles the spatial variation in life expectancy during the period when the semi-supercentenarians were born, as well as to some degree current spatial variation in life expectancy at age 80 . These findings might be interpreted as support for the argument that early ${ }^{16}$ and late life contextual conditions are very relevant in explaining spatial variation of exceptional longevity in Germany. However, our findings on spatial contextual conditions are less conclusive compared to findings on the influence of temporal variation in contextual conditions (Scholz, 2005). Also alternative explanations, such as genetic variations, cannot be ruled out.

Developments over the coming decades might provide us with additional insights into the question of to what extent contextual or genetic differences are relevant for understanding spatial variation in exceptional longevity in Germany. If the contextual effects of early life conditions are very important for reaching exceptional longevity, we would expect to find that the spatial hot spot in north-western Germany and Berlin will disappear over time, as spatial

\footnotetext{
${ }^{16}$ Actually, according to official statistics Sardinia was also the Italian region with the lowest levels of infant mortality in the late 19th century (ISTAT, 1975).
} 
variation in infant mortality substantially decreased in Germany for the cohorts born after 1925 (German Empire Statistical Office). In this case, we would expect the hot spots of exceptional longevity to move to the south, where the highest life expectancy levels are currently recorded. If spatial variation in genetic factors has an impact on the probability of surviving to high ages, we might expect the hot spot in north-western Germany to persist over time. However, if the longevity revolution continues over the coming decades, reaching age 105 might lose its status as a highly selective rare event, which might make it necessary to look at even higher ages $(107+/ 110+)$ in order to detect a pattern.

\section{Acknowledgements}

The authors would like to thank Heiner Maier and Vladimir M. Shkolnikov for comments and suggestions on earlier versions of this paper.

\section{References}

Anselin, L.; Lozano, N.; Koschinsky, J (2006): Rate Transformations and Smoothing. Urbana. In: http://geodacenter.asu.edu/pdf/smoothing_06.pdf

Bailey, T.; Gatrell, A. (1995): Interactive Spatial Data Analysis, Harlow: Longman, pp. 303 306.

Banerjee, S. (2005): On Geodetic Distance Computations in Spatial Modeling. In: Biometrics 61, pp. $617-625$.

BKG [Bundesamt für Kartographie und Geodäsie] (2007): VG 250 -Verwaltungsgebiete (Ebenen) 1 : 250000 (Stand: 31.12.2006). Frankfurt am Main: Bundesamt für Kartographie und Geodäsie.

BKG[Bundesamt für Kartographie und Geodäsie] (2009): VG 2500 -Verwaltungsgebiete (Ebenen) 1 : 2500000 (Stand: 31.12.2009). Frankfurt am Main.

Burger, O.; Baudisch, A.; Vaupel, J.W. (2012): Human mortality improvement in evolutionary context. In: Proceedings of the National Academy of Sciences 109(44), 1821018214. 
Clausson, B.; Lichtenstein, P.; Cnattingius, S. (2005): Genetic Influence on Birthweight and Gestational Length Determined by Studies in Offspring of Twins. In: BJOG: An International Journal of Obstetrics and Gynecology 107(3), pp. 375 - 381.

Cockerham, W.C.; Yamori, Y. (2001): Okinawa: An Exception to the Social Gradient of Life Expectancy in Japan. In: Asia Pacific Journal of Clinical Nutrition 10(2), pp. 154-158.

Doblhammer, G.; Scholz, R.D.; Maier, H. (2005): Month of Birth and Survival to Age 105+: Evidence from the Age Validation Study of German Semi-supercentenarians. In: Experimental Gerontology 40(10), pp. 829 - 835.

FDZ [Forschungsdatenzentrum der Statistischen Ämter des Bundes und der Länder] (2012): Geburtenstatistik 2009, own calculations.

FDZ RV [Forschungsdatenzentrum der Deutschen Rentenversicherung Bund] (2008): Postrentenbestand 2005, own calculations.

Geissler, A. (1884): Alte Leute in Sachsen, ihre Lebensstellung und Beruf. In: Zeitschrift des Königlich Sächsischen Statistischen Bureaus 30, p. 11 - 19.

German Empire Statistical Office (1901): Die Eheschließungen, Geburten und Sterbefälle im Jahre 1899. In: Vierteljahreshefte zur Statistik des Deutschen Reiches 10(1), pp. 195 234.

German Empire Statistical Office: Statistisches Jahrbuch für das Deutsche Reich (Bände 1919-1939). Berlin.

Goodchild, M.F.; Lam, N. S.-N. (1980). Areal Interpolation: A Variant of the Traditional Spatial Problem. In: Geo-Processing 1, 297-312.

Hjelmborg, J.vB.; Iachine, I.; Skytthe, A.; Vaupel, J.W.; McGue, M.; Koskenvuo, M.; Kaprio, J.; Pedersen, N.I.; Christensen, K. (2006): Genetic Influence on Human Lifespan and Longevity. In: Human Genetics 119, pp. 312 - 321.

Istat [Istituto Centrale di Statistica] (1975): Tendenze Evolutive della Mortalità Infantile in Italia. Rome.

Kirchberger, S. (1994): Health care technology in the Federal Republic of Germany. In: Health Policy 30, pp. 163 - 205. 
Klüsener, S.; Goldstein, J.R.; Hiller, A. (2012): The MPIDR Population History GIS Collection: A New Research Tool to Analyze Social Structures and Processes in Space and Time. Rostock. MPIDR Working Paper [forthcoming].

Koupilová, I.; Vågerö, D.; Leon, D.A.; Pikhart, H.; Prí́kasky, V.; Holcík, J.; Bobák, M. (1998): Social Variation in Size at Birth and Preterm Delivery in the Czech Republic and Sweden, 1989-1991. In: Paediatric and Perinatal Epidemilogy 12(1), pp. 7 - 24.

Koupilová, I.; Rahu, K.; Rahu, M. ; Karro, H.; Leon, D.A. (2000): Social Determinants of Birth Weight and Length of Gestation in Estonia during the Transition to Democracy. In: International Journal of Epidemiology 29(1), pp. 118 - 124.

Laux, H.D. (2001): Bevölkerungsverteilung. In: Institut für Länderkunde (Ed.): Nationalatlas Bundesrepublik Deutschland : Band 4 Bevölkerung (mitherausgegeben durch Gans, P.; Kemper, F.-J.). Leipzig, pp. 32 - 35.

Maier, H.; Scholz, R.D. (2010): Age Validation of Persons Aged 105 and above in Germany. In: Maier, H.; Gampe, J.; Jeune, B.; Robine, J.-M.; Vaupel, J. W. (eds.): Supercentenarians. Berlin.

Maier, H.; Scholz, R.D. (2003): Aktuelle Sterblichkeitsentwicklungen und extreme Langlebigkeit. In: CD-ROM „Max-Planck-Gesellschaft 2003: Tätigkeitsberichte, Zahlen, Fakten“ zum Jahrbuch 2003, Max-Planck- Gesellschaft (ed.). Saur, München 2003, pp. 229-235.

Maier, H.; Scholz, R.D. (2004): Immer mehr Menschen können 105. Geburtstag feiern. Studie zur Langlebigkeit der ältesten Deutschen: Zahl der Höchstaltrigen nimmt rapide zu. In: Demografische Forschung Aus Erster Hand 1(1), p. 4. http://www.demografischeforschung.org/archiv/defo0401.pdf.

Marshall, R.M. (1991): Mapping Disease and Mortality Rates Using Empirical Bayes Smoother. In: Applied Statistics 40, pp. 283 - 294.

Minnesota Population Center (2011): Integrated Public Use Microdata Series, International: Version 6.1 [Machine-readable database]: 10\%-samples of Swiss Censuses of 1970, 1980, 1990 and 2000 provided by the Federal Statistical Office. Minneapolis.

Openshaw, S. (1983): The Modifiable Areal Unit Problem. In: Concepts and Techniques in Modern Geography 38. Norwich: Geo Books. 
Pes. G.M.; Tolu, F. ; Poulain, M. et al. (2011): Lifestyle and Nutrition Related to Male Longevity in Sardinia: An Ecological Study. In: Nutrition, Metabolism and Cardiovascular Diseases [in press].

Poulain, M. (2011): Exceptional Longevity in Okinawa: A Plea for In-depth Validation. In: Demographic Research 25, pp. 245 - 284.

Scholz, R.D. (2003): Regionale Verteilung der Hochaltrigen (105+) in Deutschland, Vortrag Statistische Woche 2003 in Potsdam.

Scholz, R.D.; Maier, H. (2004): German Age Validation Study 105+ and Official Statistics: A Comparison. Presented: 5th Workshop on Supercentenarians Tokio.

Scholz, R.D.; Doblhammer, G.; Maier, H. (2005): Winterkinder besser gerüstet gegen Krankheiten: Geburtsmonat wirkt sich in Deutschland noch bis zum Lebensalter von 105 Jahren aus. In: Demografische Forschung Aus Erster Hand, 2(3), p. 4.

Sebastiani P.; Solovieff, N.; DeWan, A.; Walsh, K.M.; Puca, A.; Hartley, S.W.; Melista, E.; Andersen, S.; Dworkis, D.A.; Wilk, J.B.; Myers, R.H.; Steinberg, M.H.; Montano, M.; Baldwin, C.T.; Hoh, J.; Perls, T.T. (2012): Genetic Signatures of Exceptional Longevity in Humans. In: PLOS One 7(1), pp. 1 - 22.

SB [Statistisches Bundesamt] (2012): Periodensterbetafeln für Deutschland: Allgemeine Sterbetafeln, abgekürzte Sterbetafeln und Sterbetafeln 1871-1881 bis 2008/2010. Wiesbaden.

Tobler, W.R. (1970): A Computer Movie Simulating Urban Growth in the Detroit Region. In: Economic Geography 46, pp. $234-240$.

Willcox, D.C.; Willcox, B.J.; Todoriki, H; Curb, J.D.; Suzuki, M. (2006): Caloric Restriction and Human Longevity: What Can we Learn from the Okinawans. In: Biogerontology 2006(7), pp. $173-177$.

Willcox, D.C.; Willcox, B.J.; He, Q.; Wang, N.; Suzuki, M. (2008): They Really are that Old: A Validation Study of Centenarian Prevalence in Okinawa. In: The Journals of Gerontology: Series A 63(4), pp. 338-349. 
Fig 1: Distance between Place of Birth and Place of Death

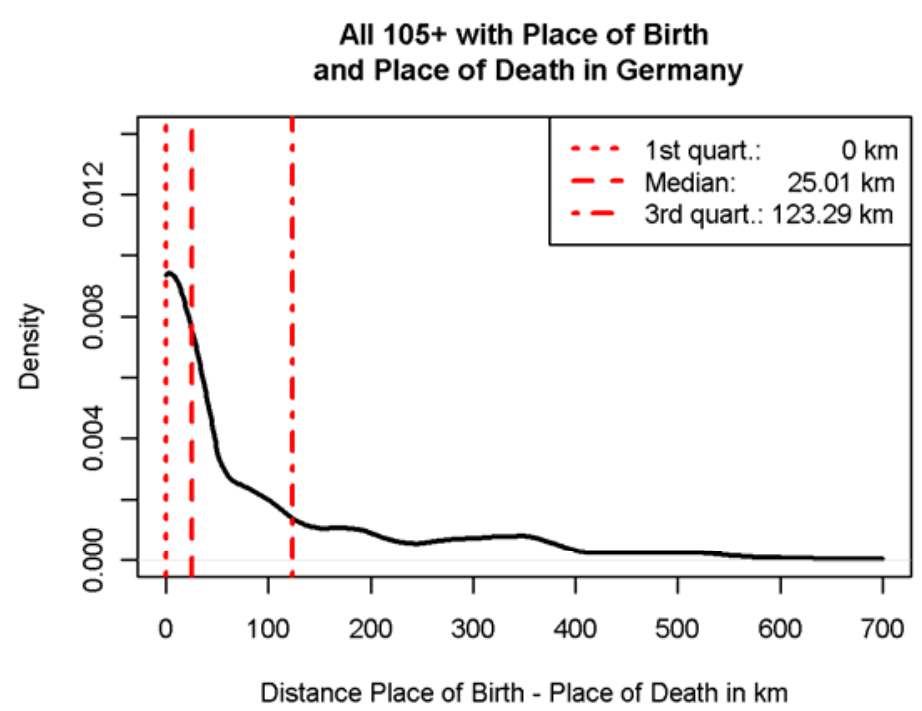

By Place of Birth in Western/Eastern Germany

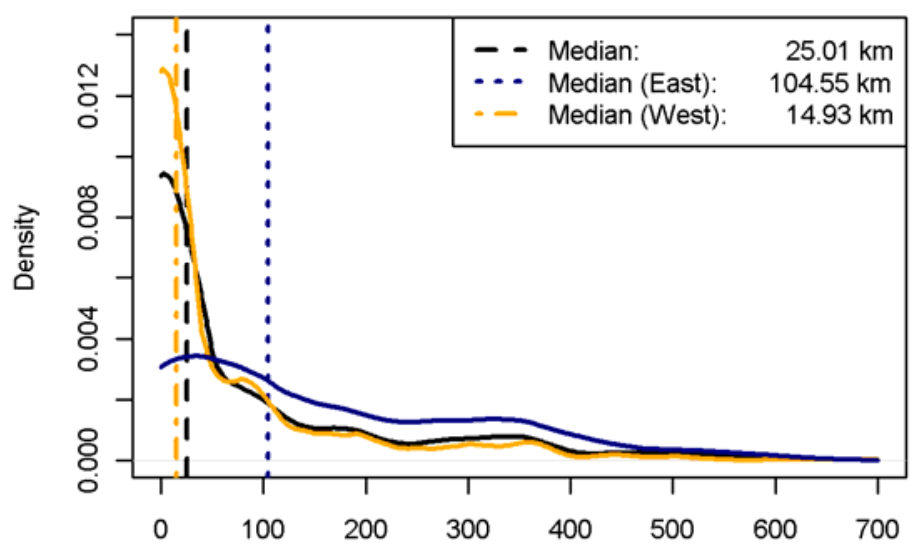

Distance Place of Birth - Place of Death in km

By Place of Death in Four Biggest Cities (BER,HAM,MUC,COL)/Other Places

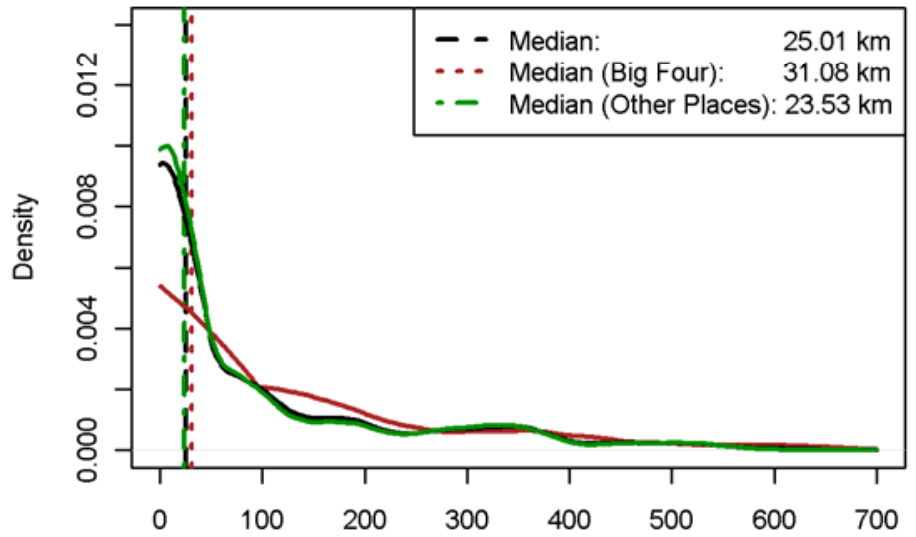

Distance Place of Birth - Place of Death in km

Source: Age validation study 105 +Germany; FACG (2007); Own calculations 
Fig 2: "Hot Spots" of Exceptional Longevity in Germany by Place of Birth and Place of Death
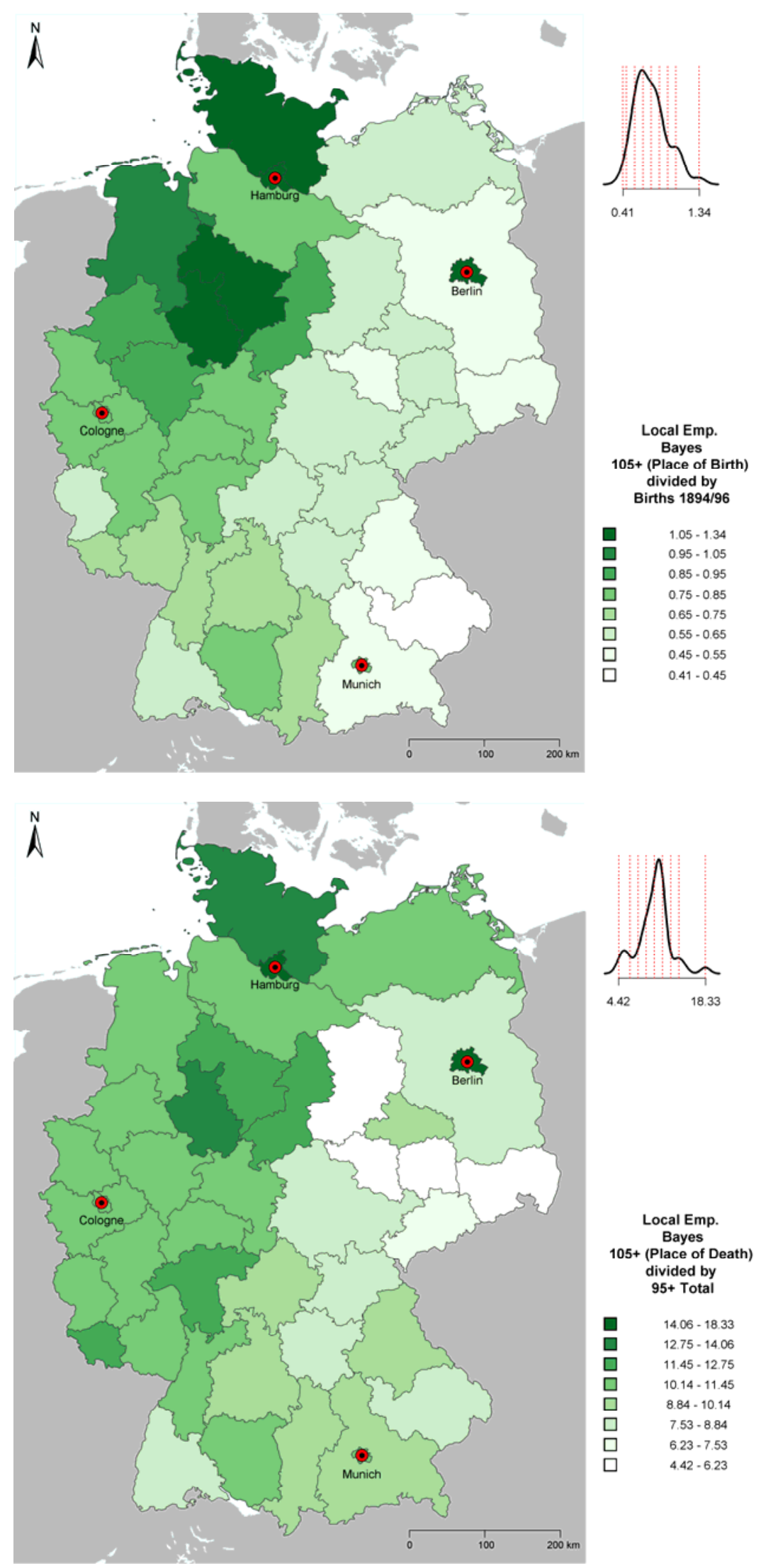

Source: Age validation study $105+$ +Germany; German Empire Statistical Office (1901);

FDZ RV (2008); Own calculations Base Map: MPIDR Population History Collection (partly based on FACG, 2009) 
Fig. 3 Female Life Expectancy at Birth 1891-1900 vs. 2000

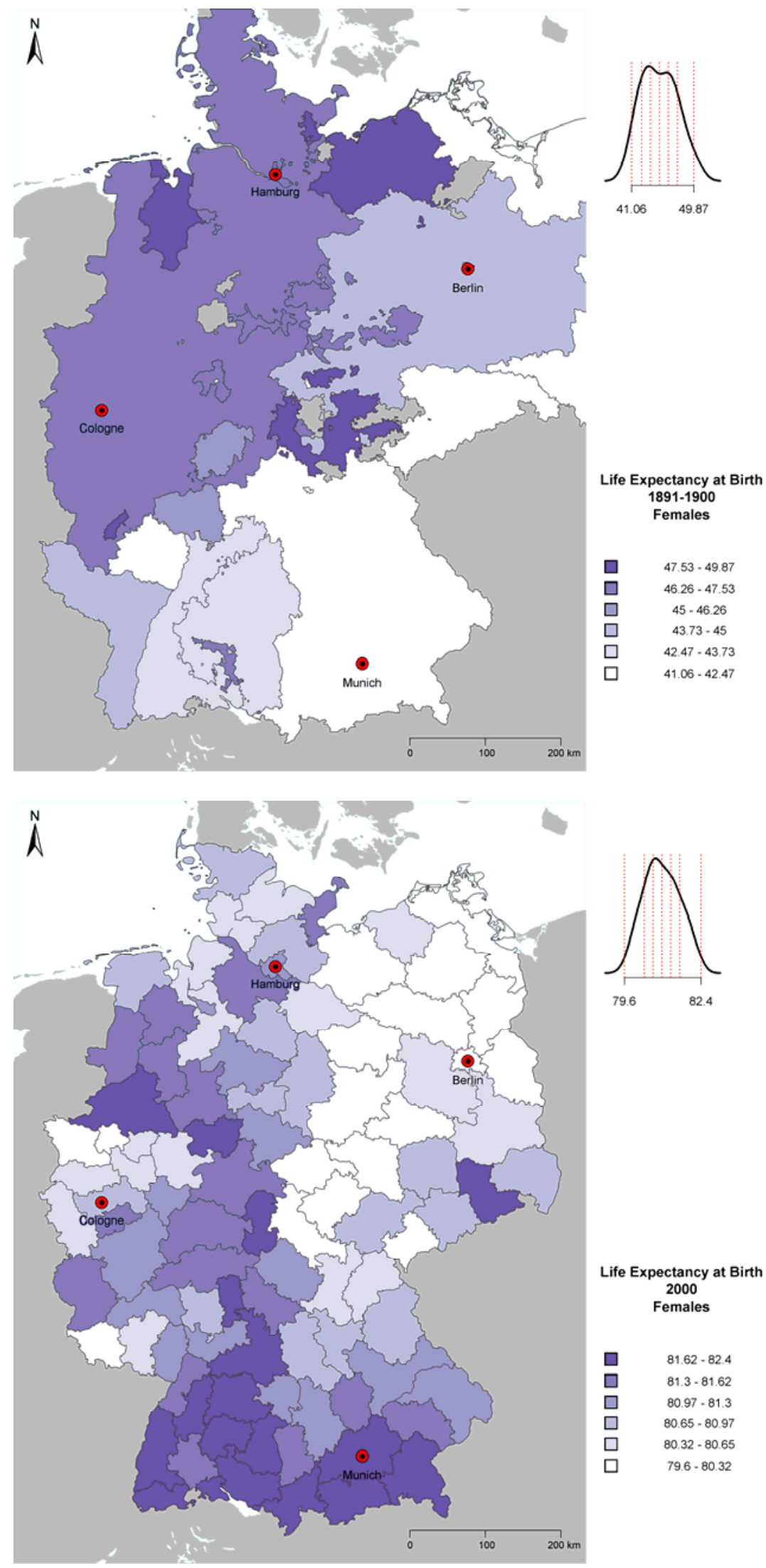

Source: German Empire Statistical Office; INKAR Database; Own Calculations Base Map: MPIDR Population History Collection (partly based on FACG, 2009) 
Fig. 4 Spatial Variation in Birth Weight and Birth Length
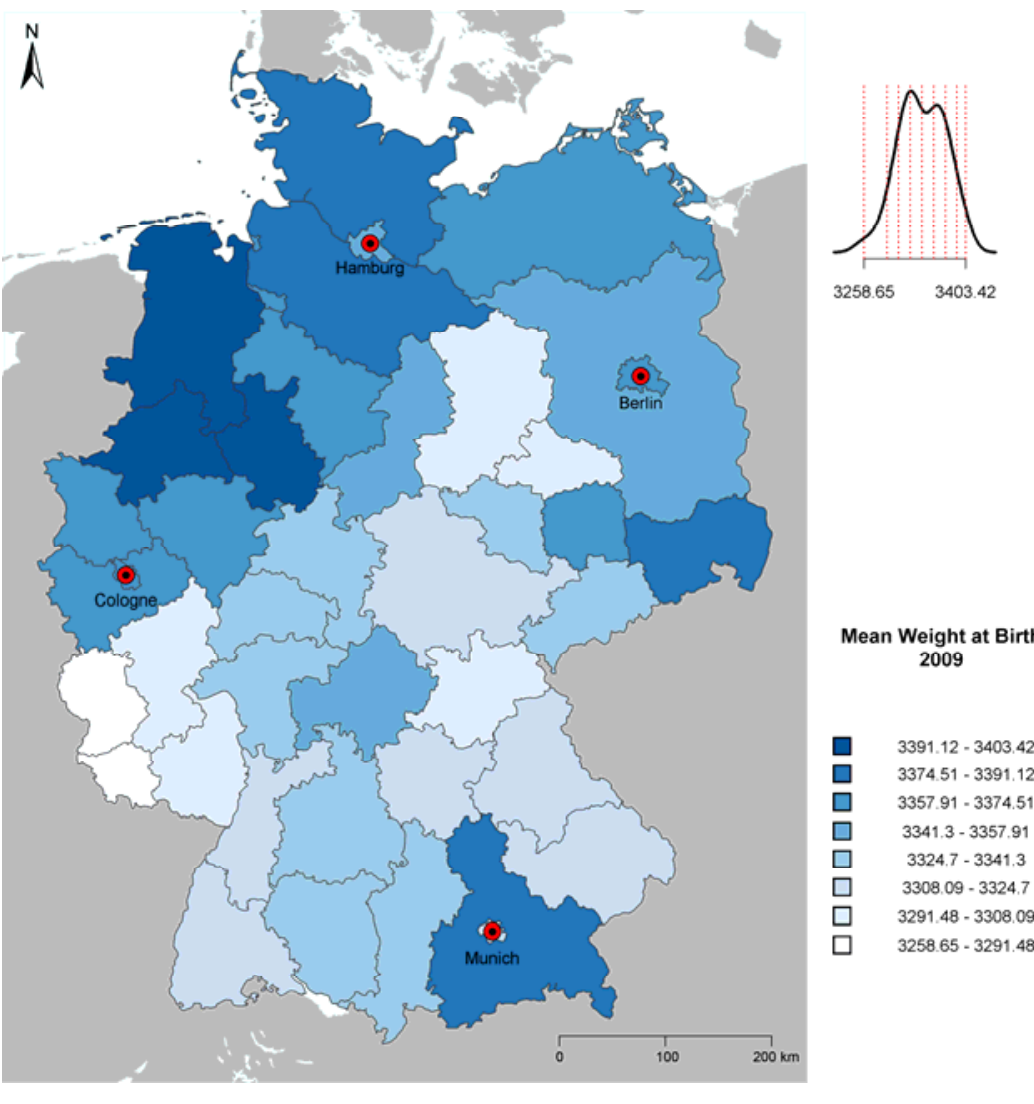

Mean Weight at Birth 2009

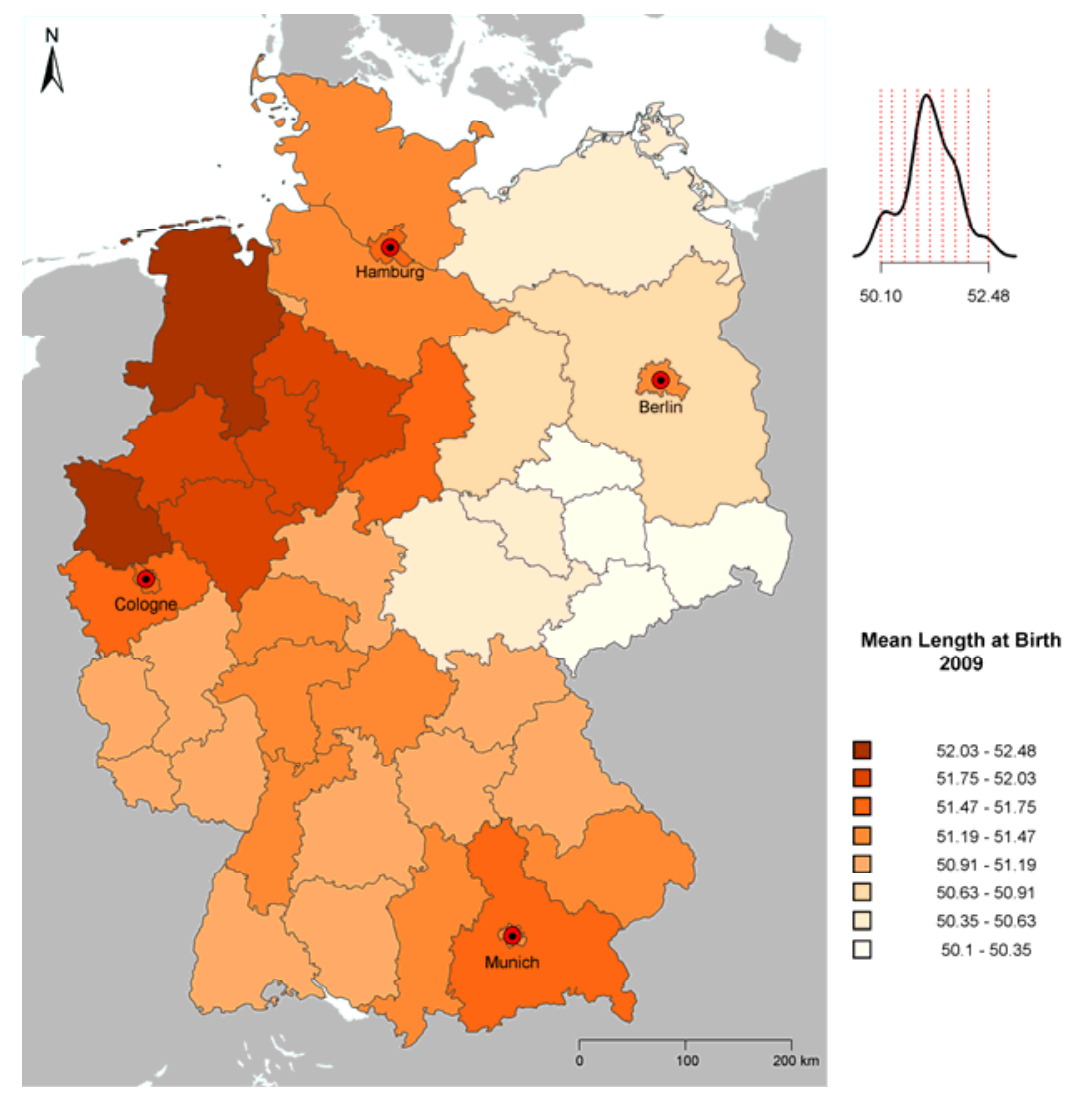

Source: FDZ 2012; Own calculations Base Map: MPIDR Population History Collection (partly based on FACG, 2009) 